\title{
Vaccinating poultry against avian flu is contributing to spread
}

Jane Parry Hong Kong

\begin{abstract}
Inappropriate use of vaccination in poultry to try to prevent the spread of bird flu has become part of the problem and has serious human health implications, officials of the World Health Organization warned this week.

"Vaccination can sometimes cause silent transmission of infection from asymptomatic birds. Mass vaccination programmes entail people tramping around the countryside from farm to farm and they can spread the disease with them. The first response must be culling," said Peter Cordingley, WHO's spokesman in Manila.

Although no vaccine has yet been approved for use in humans, birds have been vaccinated against the disease for about four years. The Chinese government has said that it intends to vaccinate all its four billion chickens. The Indonesian government has said that it did not have the resources to control the outbreak by culling because it could not afford to compensate farmers.
\end{abstract}

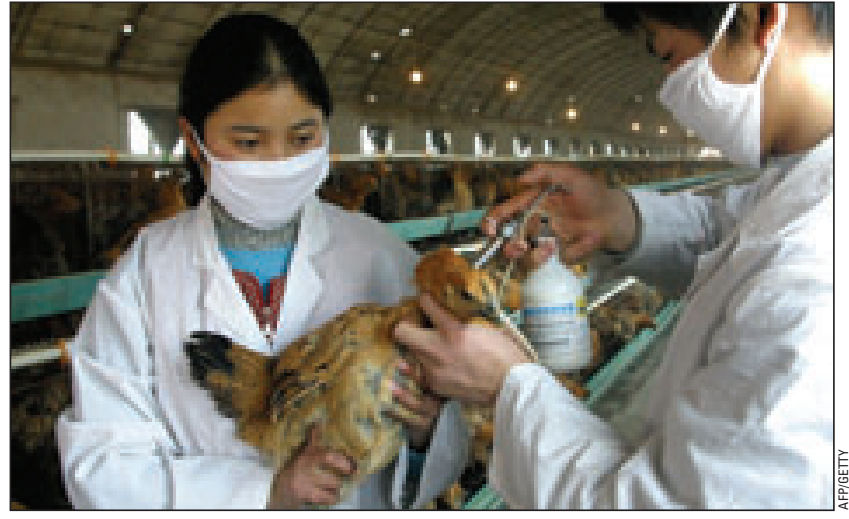

Following two human deaths from avian flu, China has said that it intends to vaccinate all its four billion chickens

China's announcement on mass vaccination of birds came in the same week that its Ministry of Health confirmed the country's first two human cases of $\mathrm{H} 5 \mathrm{~N} 1$ avian flu, one of them fatal. Two new confirmed human cases, both fatal, have also been reported in Indonesia. A 20 year old woman and a 16 year old girl died in early
November in Jakarta, taking the country's death toll to seven out of 11 confirmed cases.

China's announcement has triggered a heightened state of alert in neighbouring Hong Kong, which has reintroduced temperature checks on all travellers at border points into the city, which were instituted during the 2003 outbreak of severe acute respiratory syndrome (SARS).

The two confirmed human cases of bird flu in China are in a 24 year old woman farmer from Anhui province who was hospitalised with severe pneumonia on 7 November and died three days later and a nine year old boy from a village in Hunan province, which has been afflicted with avian flu in poultry.

He has since recovered but his 12 year old sister died after being hospitalised, also for severe pneumonia. She was cremated before adequate samples could be taken to make a diagnosis.

The Chinese government had previously denied that the two children had contracted avian flu but later requested the help of the World Health Organization to investigate the deaths. The Chinese Centre for Disease Control and Prevention's laboratory in Beijing did tests, and a team of experts from WHO that visited the laboratory confirmed the results.

\section{FDA criticised for rejecting over the counter emergency contraception}

Janice Hopkins Tanne New York

The US Food and Drug Administration's decision to refuse to approve over the counter status for the emergency contraceptive Plan B (levonorgestrel) was flawed, unusual, and not standard FDA procedure. This is finding of a report by the Government Accountability Office, an independent investigative agency of the US Congress.

Two FDA officials resigned in protest over the denial (BMJ 2005;331:532, 861). Lester Crawford's approval as the FDA's commissioner was also delayed as a direct result of the furore. He resigned shortly after his confirmation but did not cite any specific issue as the reason for his decision (BMJ 2005;331:713).

Forty eight senators and representatives had asked the accountability office to investigate why the FDA had rejected over the counter status for Plan B (BMJ 2005;328:1219).

Plan B was approved for use by prescription in 1999. In April 2003, the manufacturer, Barr, applied to the FDA for over the counter status. The application was reviewed by several FDA offices and by two independent FDA advisory committees. The advisory committees voted 23 to four in favour of over the counter status, and the FDA's staff recommended approval.

But Steven Galson, then acting head of the Center for Drug Evaluation and Research (and now head) rejected the application, saying that women aged under 16 might not understand the instructions.

Barr then applied for over the counter use by older women and prescription only use for those 16 or younger. Instead, the FDA called for a period of public comment, which has just ended, and said that it would make a decision later (BMJ 2005;331:596).
The accountability office's report said that high level FDA management was more involved in considering over the counter status of Plan B than of other drugs being switched from prescription to over the counter, it said.

Planned Parenthood said that Plan B was the only drug denied a switch to over the counter use after advisory committees recommended approval. Also, there were no age restrictions on other FDA approved prescription or over the counter contraceptives.

Decision Process to Deny Application for over the Counter Marketing of the Emergency Contraceptive Drug Plan B Was Unusual, is available at www. gao.gov/new.items/d06109.pdf. 